\title{
Is Primary Care Providers' Trust in Socially Marginalized Patients Affected by Race?
}

\author{
David Moskowitz, MD' ${ }^{7}$, David H. Thom, MD PhD², David Guzman, $M S P H^{7}$, \\ Joanne Penko, MS MPH ${ }^{7}$, Christine Miaskowski, RN PhD ${ }^{3}$, and Margot Kushel, $\mathrm{MD}^{7}$ \\ 'Division of General Internal Medicine, University of California San Francisco/San Francisco General Hospital, San Francisco, CA, USA; \\ ${ }^{2}$ Department of Family \& Community Medicine, University of California San Francisco, San Francisco, CA, USA; ${ }^{3}$ Department of Physiological \\ Nursing, University of California San Francisco, San Francisco, CA, USA.
}

BACKGROUND: Interpersonal trust plays an important role in the clinic visit. Clinician trust in the patient may be especially important when prescribing opioid analgesics because of concerns about misuse. Previous studies have found that non-white patients are perceived negatively by clinicians.

OBJECTIVE: To examine whether clinicians' trust in patients differed by patients' race/ethnicity in a socially marginalized cohort.

DESIGN: Cross-sectional study of patient-clinician dyads.

PARTICIPANTS: $169 \mathrm{HIV}$ infected indigent patients recruited from the community and their 61 primary care providers (PCPs.)

MAIN MEASURES: The Physician Trust in Patients Scale (PTPS), a validated scale that measures PCPs' trust in patients.

KEY RESULTS: The mean PTPS score was 43.2 (SD 10.8) out of a possible 60. Reported current illicit drug use and prescription opioid misuse were similar across patients' race or ethnicity. However, both patient illicit drug use and patient non-white race/ethnicity were associated with lower PTPS scores. In a multivariate model, non-white race/ethnicity was independently associated with PTPS scores 6.3 points lower than whites (95\% CI: -9.9, -2.7). Current illicit drug use was associated with PTSP scores 5.5 lower than no drug use $(95 \%$ CI $-8.5,-2.5)$.

CONCLUSION: In a socially marginalized cohort, nonwhite patients were trusted less than white patients by their PCPs, despite similar rates of illicit drug use and opioid analgesic misuse. The effect was independent of illicit drug use. This finding may reflect unconscious stereotypes by PCPs and may underlie disparities in chronic pain management.

KEY WORDS: trust; communication; vulnerable populations; opioid analgesics; disparities.

J Gen Intern Med 26(8):846-51

DOI: $10.1007 / \mathrm{s} 11606-011-1672-2$

(C) The Author(s) 2011. This article is published with open access at Springerlink.com

Received October 20, 2010

Revised February 5, 2011

Accepted February 11, 2011

Published online March 11, 2011

\section{INTRODUCTION}

Interpersonal trust is an important aspect of the clinical encounter. Trust is defined as one's expectation that another will behave in a particular way ${ }^{1}$ and implies that both parties understand that each others' interests will not be violated ${ }^{2}$. It reflects reliability, understanding and information sharing, all key components of high quality communication ${ }^{3,4}$. In contrast to patients' trust in clinicians, ${ }^{3,5}$ clinicians' trust in patients has not been investigated.

While some clinical decisions are based on clear objective measures, others, such as the treatment of chronic non-cancer pain, are based on more subjective assessments. The treatment of chronic pain is further complicated by the fact that while consideration of opioid analgesics is reasonable for moderate to severe pain, their use must be balanced against the risk of opioid misuse $\mathrm{e}^{6-9}$.

A number of patient characteristics are associated with an increase risk of opioid analgesic misuse, including history of alcohol abuse or illicit drug use ${ }^{10-12}$. However, clinicians do not conform their decisions to these well described risk factors. Patients' race/ethnicity affect treatment decisions ${ }^{13-15}$. Additionally, the treatment of chronic pain varies by clinicians' experience and training 8,16 .

In qualitative studies, clinicians have identified mutual trust as an important factor influencing chronic pain management and the prescription of opioid analgesics ${ }^{7,17-19}$. Clinicians judge patients' risk of misuse based on "gut feelings" rather than on specific clinical characteristics associated with risk of misuse ${ }^{17}$. Thus, clinicians' trust in their patients may play a large role in decisions surrounding chronic pain management.

Characteristics such as patients' race/ethnicity may affect clinicians' trust. Studies have demonstrated that physicians perceive African American patients more negatively ${ }^{20}$. Assessing the relationship between patient race/ethnicity and clinician trust in the patient may be helpful in understanding the effect of race/ ethnicity on physician attitudes and behaviors. We analyzed a cohort of socially marginalized patients with HIV and their primary care providers in order to examine the association between race/ ethnicity and trust in a uniformly low SES population with high rates of illicit drug use and prescription opioid analgesic misuse.

\section{METHODS}

\section{Setting and Participants}

In order to assess clinicians' trust in patients, we conducted a dyad study that involved a subset of community-based 
indigent participants enrolled in a longitudinal observational cohort study of pain (the Pain Study) and their primary care providers (PCPs). We recruited participants for the Pain Study from the Research on Access to Care in the Homeless (REACH) study. The REACH study was a prospective cohort of HIV-infected homeless and marginally housed adults in San Francisco. The REACH cohort was recruited through systematic sampling from homeless shelters, free-meal programs, and single room-occupancy hotels ${ }^{21,22}$ in three waves (1996-1998, 1999-2000, and 2003). REACH participants were interviewed quarterly regarding illicit drug use, housing status and healthcare utilization at a research field site (University of California San Francisco's Clinical and Translational Sciences Institute Tenderloin Clinical Research Center). For the Pain Study, we recruited all REACH participants who completed study visits between September 2007 and June 2008.

The Pain Study involved a baseline visit and seven quarterly follow-up interviews that occurred every three months coinciding with REACH follow-up quarterly interviews. For the Pain Study, participants completed a structured interview about pain, opioid analgesic use and misuse, and health care utilization related to pain management. At baseline, we conducted the Diagnostic Interview Schedule-IV (DIS-IV) ${ }^{23}$ substance and alcohol modules. At each follow-up visit, participants completed the REACH questionnaire and the Pain Study Follow-up Questionnaire, a 25-minute abbreviated version of the baseline questionnaire. Trained interviewers administered all of the questionnaires, except for questions about opioid analgesic misuse, which participants completed using Audio Computer Assisted Self Interview (ACASI) technology. ACASI is an acceptable method to use with low-literacy populations and improves the reliability of sensitive information ${ }^{24}$.

We recruited one PCP for each participant who was active in follow-up one year into the study. If a participant provided informed consent to contact their PCP, and identified a provider who fit our definition (a medical doctor, nurse practitioner (NP), or physician assistant (PA) in outpatient practice providing longitudinal, comprehensive care), we contacted the PCP and asked them to complete a questionnaire about themselves and a separate questionnaire specific to each of their patients enrolled in the study. The provider-specific questionnaire included questions about the PCP's demographics and practice characteristics. The patient-specific questionnaire included questions about the patient's medical conditions, use and misuse of prescription opioid analgesics, and the Physician Trust in Patients $\mathrm{Scale}^{25}$. We recommended, but did not require, that PCPs refer to patient medical records when they completed the survey. The study was approved by the University of California San Francisco's Institutional Review Board and patients and PCPs provided written informed consent.

\section{Independent Variables: Patient-Level}

We obtained patient self-reported biological sex, date of birth, race/ethnicity and history of incarceration in state or federal prison at entry in the REACH cohort. We ascertained race/ ethnicity by having patients select racial or ethnic categories from the following list: White, African American, Latino, Asian, Native American, Pacific Islander, or mixed race. We collapsed Asian, Native American, Pacific Islander and mixed race into a single category due to the small number of respondents in each of these categories. We measured alcohol abuse and dependence through responses to the DIS-IV ${ }^{23}$. In the DIS-IV, alcohol abuse and dependence is defined in a manner consistent with the Diagnostic and Statistical Manual of Mental Disorders ${ }^{26}$. We assessed current use of illicit drugs using responses from the patient's REACH questionnaire completed closest in time to the PCP's completed questionnaire. We defined current use as a "yes" response to questions about use of cocaine, heroin or methamphetamines in the past 90 days. We combined use of cocaine, heroin or methamphetamine into a single variable, as we hypothesized that PCPs would not distinguish between the three categories with regard to trust $^{10}$

We measured opioid analgesic misuse through patients' responses to yes/no questions about specific misuse behaviors using ACASI technology ${ }^{27}$. Items addressed using opioid analgesics to get high; trading them for money, illicit drugs or sex; lying to their PCP about opioid analgesics; forging prescriptions for opioids; or augmenting the effect of prescription opioid analgesics with illicit drugs or alcohol. We aggregated responses, defining misuse as an affirmative answer to any one of these questions on the Pain Study questionnaire completed closest in time to the PCP survey.

\section{Independent Variables: Clinician-Level}

In addition to PCPs' sex, age, race and ethnicity, we evaluated years in practice and training (physician, PA or NP.) We asked each PCP to estimate the proportion of their patient panel with chronic pain. We collapsed PA and NP into a single category. We collapsed PCP race and ethnicity into two categories, nonLatino white and all others, owing to the small number of PCPs who were of minority racial or ethnic groups. We recorded years in practice as a categorical variable: 0 to 3,4 to 9,10 to 19 and 20 or greater.

\section{Dependent Variable}

We measured PCPs' trust in patients with the Physician Trust in the Patient Scale (PTPS), which was validated in the Pain Study cohort ${ }^{25}$. The PTPS has high internal reliability with a Cronbach's alpha of 0.93 and was shown to have convergent validity with clinician reported perceptions of patients' behaviors expected to be associated with lower levels of trust.

The PTPS consists of 12 questions that are rated on a 5point Likert scale with responses that range from $(0$, "not at all confident") to (5, "completely confident") (Text Box). A total score is the sum of the 12 items that can range from 0 to 60 . Higher scores indicate greater perceptions of trust. 


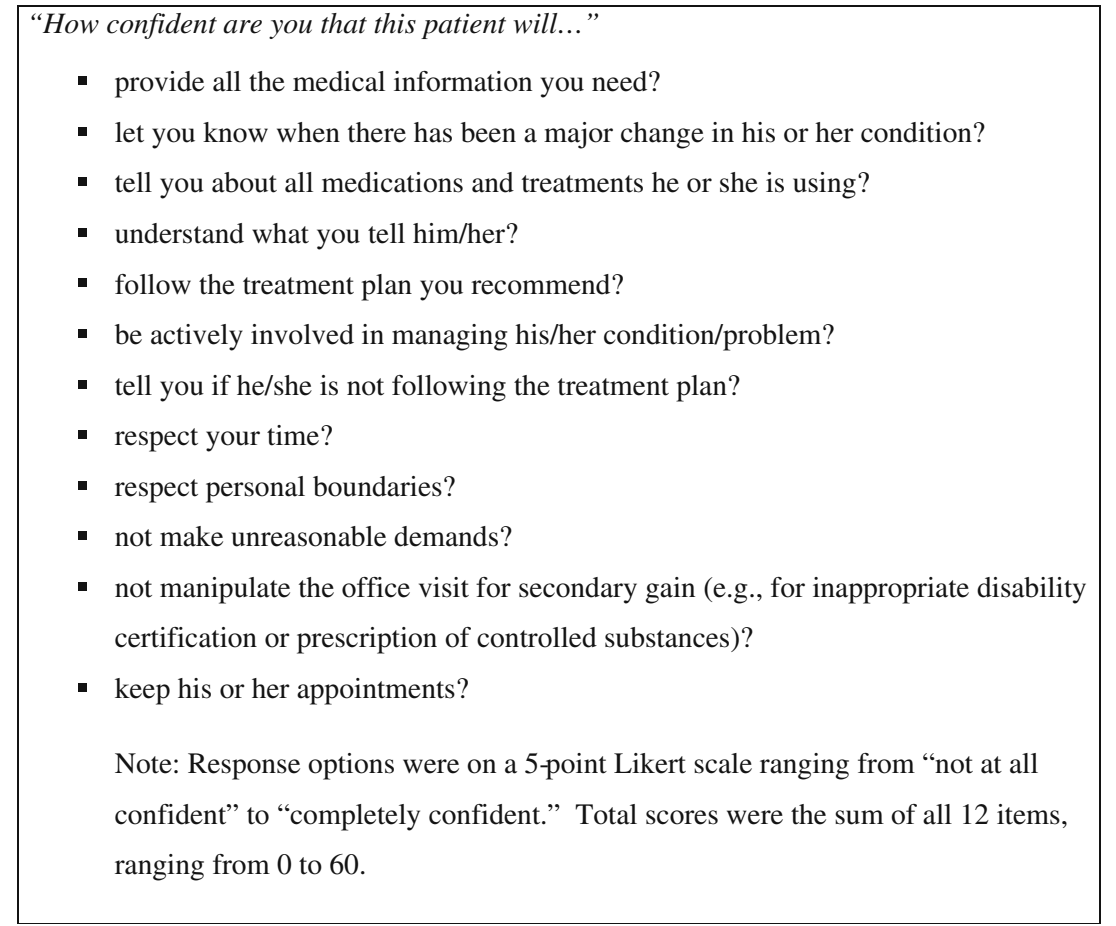

Text Box. Physician Trust in Patient Scale (PTPS) questions.

\section{Analysis}

Our main analytic goal was to estimate the association of patient race/ethnicity and PTPS scores. We selected independent variables a priori that might confound the relationship between patient race/ethnicity and PCPs' trust in patients. We entered all variables into the model simultaneously. After testing confirmed that all non-white patient groups had lower PTPS scores, we collapsed them for the multivariate analysis. We analyzed bivariate and multivariate associations using generalized estimating equations, an extension of the linear model providing robust standard errors, p-values, and confidence intervals that account for the correlation among the multiple responses of each PCP for a panel of patients ${ }^{28,29}$.

\section{RESULTS}

Of the 296 patients initially enrolled in the Pain Study, 240 were active in the study at one year and provided written consent that allowed us to contact their PCP. We contacted a total of 90 PCPs for these patients of whom 61 PCPs returned completed questionnaires for a total of 169 patients.

Two-thirds of patients were male $(65.1 \%)$, half were African American (46.8\%), and their average age was 50 years. Approximately one quarter $(27.8 \%)$ reported current use of illicit drugs. Approximately one quarter (22.5\%) reported misusing opioid analgesics in the past 90 days. Most had experienced homelessness (82.0\%) though few were homeless at the time of the study (5.0\%). Most had a high school education or less $(73.4 \%)$. The median annual income was $\$ 11,280$. PCPs were mostly white $(78.3 \%)$. Approximately half (46.0\%) were male. The majority were in practice between 10 and 19 years. None were in practice fewer than four years. Most (83.6\%) were physicians (Table 1 ).

The prevalence of current illicit drug use as well as opioid analgesic misuse did not differ in a manner that was statistically significant between racial or ethnic groups $(p=0.71$ and $p=0.18$ respectively). The mean PTPS score was 43.2 (SD 10.8.) Bivariate models showed an association of both African American and "other" patient race with lower mean PTPS scores, as well as an association between current illicit drug use, as reported by the patient and lower mean PTPS scores (Table 1). Bivariate models showed a trend towards lower PTPS scores among patients who reported opioid analgesic misuse although the effect did not reach statistical significance.

In the adjusted multivariate analysis, non-white patient race/ ethnicity was significantly associated with lower PTPS scores (Table 2). Current drug use was also associated with lower PTPS scores $(p<0.01)$. Opioid analgesic misuse was not significantly associated with differences in PTPS scores $(p<0.01)$. PCPs with more than 20 years in practice rated patients as having significantly lower PTPS scores $(p<0.05)$. The test for trend across categories was significant at $p<0.05$. The Wald statistic for the multivariate model was 52.4 with $p<0.001$.

\section{DISCUSSION}

Our study found that in a cohort of socially marginalized patients with HIV infection receiving primary care, PCPs 
Table 1. Patient $(n=169)$ and Provider $(n=61)$ Demographic Characteristics, and Unadjusted Association of Predictors with Physicians' Trust in Patients Scale (PTSP) Scores

\begin{tabular}{|c|c|c|c|}
\hline & n (\%) & $\begin{array}{l}\text { PTPS score } \\
\text { (SE) }\end{array}$ & $p$ \\
\hline Total sample (mean, SD) & - & $43.2(10.8)$ & - \\
\hline Patient age (years, SD) & $49.5(6.9)$ & $0.1(0.1)^{*}$ & 0.52 \\
\hline \multicolumn{4}{|l|}{ Patient sex } \\
\hline Male & $110(65)$ & $44(1.1)$ & - \\
\hline Female & 59 (35) & $42(1.5)$ & 0.26 \\
\hline $\begin{array}{l}\text { Annual income } \\
\text { (median, IQR) }\end{array}$ & $\begin{array}{l}11,280(10,440, \\
11,904)\end{array}$ & - & - \\
\hline \multicolumn{4}{|l|}{ Education } \\
\hline Less than high school & $49(29)$ & - & - \\
\hline Finished high school & $75(45)$ & - & - \\
\hline $\begin{array}{l}\text { Greater than high } \\
\text { school }\end{array}$ & $44(26)$ & - & - \\
\hline \multicolumn{4}{|l|}{ Patient race/ethnicity } \\
\hline White & $60(36)$ & $47.3(1.4)$ & - \\
\hline African American & $79(47)$ & $41.6(1.2)$ & $<0.001$ \\
\hline Latino & $12(7)$ & $42.8(2.5)$ & 0.11 \\
\hline Other & $13(8)$ & $35.9(2.9)$ & $<0.001$ \\
\hline \multicolumn{4}{|l|}{$\begin{array}{l}\text { Opioid analgesic } \\
\text { misuse }^{\dagger}\end{array}$} \\
\hline No & $73(43)$ & $44.3(2.0)$ & - \\
\hline Yes & $96(57)$ & $39.7(1.8)$ & 0.03 \\
\hline \multicolumn{4}{|l|}{ Current drug use ${ }^{\ddagger}$} \\
\hline No & $122(72)$ & $44.8(1.0)$ & - \\
\hline Yes & $47(28)$ & $39.2(1.6)$ & $<0.01$ \\
\hline \multicolumn{4}{|l|}{$\begin{array}{l}\text { Lifetime alcohol abuse } \\
\text { or dependence } \\
\S\end{array}$} \\
\hline No & $68(41)$ & $43.3(1.4)$ & - \\
\hline Yes & 96 (59) & $43.2(1.27)$ & 0.93 \\
\hline $\begin{array}{l}\text { Lifetime history } \\
\text { of homelessness }\end{array}$ & $136(82)$ & - & - \\
\hline $\begin{array}{l}\text { Homeless at time } \\
\text { of interview }\end{array}$ & $10(5)$ & - & - \\
\hline Incarceration (prison) & $25(16)$ & - & - \\
\hline \multicolumn{4}{|l|}{ Provider sex } \\
\hline Male & $28(46)$ & $44.1(1.27)$ & - \\
\hline Female & $33(54)$ & $42.5(1.25)$ & 0.35 \\
\hline Provider age (years, s.d.) & $46.7(8.3)$ & - & - \\
\hline \multicolumn{4}{|l|}{ Provider race/ethnicity } \\
\hline White & $47(71)$ & $43.2(1.0)$ & - \\
\hline Non-white & $13(29)$ & $43.3(1.9)$ & 0.97 \\
\hline \multicolumn{4}{|l|}{ Provider type } \\
\hline $\mathrm{PA} / \mathrm{NP}$ & $10(16)$ & $45.1(1.8)$ & - \\
\hline $\mathrm{MD}$ & $51(84)$ & $42.7(1.0)$ & 0.23 \\
\hline \multicolumn{4}{|l|}{ Years in practice } \\
\hline 4 to 9 & $11(18)$ & $45.2(2.6)$ & - \\
\hline 10 to 19 & $31(51)$ & $43.6(1.1)$ & 0.57 \\
\hline$>20$ & $19(31)$ & $41.9(1.4)$ & 0.28 \\
\hline \multicolumn{4}{|l|}{$\begin{array}{l}\text { Clinic panel with } \\
\text { chronic pain }\end{array}$} \\
\hline Some & $29(48)$ & $43.8(1.4)$ & - \\
\hline About half & $24(39)$ & $41.8(1.3)$ & 0.32 \\
\hline Most to almost all & $8(13)$ & $45.3(1.9)$ & 0.52 \\
\hline
\end{tabular}

${ }^{*}$ Change in PTPS per 1 year change in patient age

${ }^{\dagger}$ Answering yes to any of the following in the past 90 days: using opioid analgesics to get high; trading them for money, illicit drugs or sex; lying to their PCP about opioid analgesics; forging prescriptions for opioids; or augmenting the effect of prescription opioid analgesics with illicit drugs or alcohol

"Answering "yes" to having used cocaine, heroin or methamphetamines in the past 90 days

${ }^{\S}$ DIS-IV criteria

reported less trust of patients with a history of illicit drug use and patients who were of non-white race/ethnicities. Our findings are consistent with studies that suggest variations in PCPs' attitudes and prescribing decisions in different racial groups with chronic pain ${ }^{14,30}$. They extend the literature by specifically investigating the construct of trust within a low socioeconomic status cohort. In this sample, where every patient is indigent and many have significant illicit substance use and incarceration histories-and therefore is at higher than average risk for opioid analgesic misuse-one might not expect such variation in trust scores across different racial/ ethnic groups. Our finding of attitudes of distrust towards non-white patients is consistent with studies of the general population ${ }^{31-33}$. In our study sample, rates of illicit substance use and opioid analgesic misuse were similar among racial groups. This finding is consistent with previous reports that showed that African Americans are no more likely to misuse prescription opioid analgesics than are whites ${ }^{10}$.

Trust in patients represents an important component of the clinical encounter and may serve as a provider-level mediator of disparities in care ${ }^{34}$. Even in this study of socially marginalized patients, PCPs' trust in patients appears to be guided in part by perceptions of racial/ethnic groups, and not solely by individual patients' illicit drug use or opioid analgesic misuse. Trust is based on a subjective assessment of the patient, and may be influenced by unconscious biases and stereotypes. Clinical situations with high degrees of "cognitive load" (e.g. risk, stress, uncertainty) generally increase providers reliance on biases and stereotypes ${ }^{35,36}$. Chronic pain management, with the possibility of medication diversion and the simultaneous concern of under-treatment of pain, presents just such a situation. Thus, PCPs' differential trust of non-white patients' in a cohort of indigent patients might underlie well demonstrated disparities in pain management ${ }^{13,37-39}$.

The risk, uncertainty, and lack of objective findings that typify the management of chronic pain are not unique to this

Table 2. Multivariate Model for Physicians' Trust in Patients Scale (PTPS) Scores

\begin{tabular}{lcr}
\hline \hline & $\begin{array}{l}\text { Change in PTPS score } \\
(95 \% \mathrm{Cl})\end{array}$ & $p$ \\
\hline Patient & & \\
Female & $3.1(-1.1,7.2)$ & 0.15 \\
Age (years) & $0.1(-0.1,0.3)$ & 0.45 \\
Non-white & $-6.3(-9.9,-2.7)$ & $<0.01$ \\
Opioid analgesic misuse & $-4.7(-10.1,0.7)$ & 0.09 \\
Current drug use & & $<0.01$ \\
Lifetime alcohol abuse & $-5.5(-8.5,-2.5)$ & 0.42 \\
$\quad$ or dependence & $1.2(-1.7,4.1)$ & \\
Provider & & 0.62 \\
Female & $-1.1(-5.3,3.1)$ & 0.76 \\
Non-white & $0.6(-3.3,4.4)$ & \\
Physician & $-2.7(-7.9,2.4)$ & 0.29 \\
Years in practice & 0 & 0.31 \\
4 to 9 & 0 & \\
10 to 19 & $-2.6(-7.7,2.4)$ & \\
$>$ 20 & $-6.8(-12.2,-1.5)$ & 0.88 \\
Clinic panel with chronic pain & & 0.29 \\
Some & 0 & \\
About half & $0.3(-3.6,4.2)$ & \\
Most to almost all & $2.3(-1.9,6.5)$ & \\
\hline
\end{tabular}

"Answering yes to any of the following in the past 90 days: using opioid analgesics to get high; trading them for money, illicit drugs or sex; lying to their PCP about opioid analgesics; forging prescriptions for opioids; or augmenting the effect of prescription opioid analgesics with illicit drugs or alcohol

'Answering "yes" to having used cocaine, heroin or methamphetamines in the past 90 days

${ }^{\ddagger}$ DIS-IV criteria 
condition. Many conditions commonly encountered in primary care lack clear objective findings and are managed very differently between providers. Therefore, it is likely that trust in patients plays a role in many other clinical decisions.

Aside from clinical uncertainty, there are two characteristics of trust in patients that make it particularly relevant to clinical decision-making. First, the construct of trust is future oriented: it involves an expectation of future actions ${ }^{40,41}$. Especially in primary care relationships that involve prevention or management of chronic diseases, differential expectations of patients' future actions have the potential to modify clinical decisions such as medication intensification. Second, trust is closely related to power. Communication strategies such as patient-centered communication, where the patient's perspective is elicited and incorporated into decision making, requires sharing power and responsibility ${ }^{42}$. Clinicians' trust of their patient is a necessary step in this process ${ }^{2}$. Differences in trust may affect the degree to which patient-centered communication can be achieved.

PCPs who were in practice longer reported lower trust scores of his or her patients. It is possible that an accumulation of negative experiences with patients may lead to decreases in trust. Alternatively, this association may represent broader issues of decreased professional satisfaction, more prevalent among older providers ${ }^{43}$. Finally, while our study was underpowered to explore whether the length of time in practice differentially affected trust in patients by race/ethnicity, a third potential explanation is that recent increased emphasis in educational settings about disparities and biases/stereotypes has led to more recently trained providers' greater trust scores.

Our findings speak to the need to better train clinicians in how to recognize and account for unconscious racial biases and stereotypes. Unconscious attitudes represent an important aspect of disparities education. Training about assumptions and biases may be best integrated into teaching clinical decision-making: increasing clinicians' awareness of biases and encouraging careful consideration of decisions based on intuition. Alternatively, tests of implicit assumptions may serve an educational role in increasing clinicians' self-awareness of unconscious biases ${ }^{44}$.

Several limitations need to be acknowledged. The social marginalization of patients (marginally housed, HIV infected, with high rates of illicit drug use) limits the generalizability of findings to other populations. Our sample size was relatively small and, in particular, the number of non-white PCPs was small. This limited our ability to analyze patient-clinician racial/ ethnic concordance, an important contributor to processes of care $^{45}$. Finally, although socioeconomic status (SES) is a common confounder of race and affects PCPs' perceptions, ${ }^{20}$ the uniformly low SES of the patients in this study decreases the chance of SES confounding the relationship.

Findings from this study suggest that patients' race/ethnicity affects PCPs' trust in patients in a socially marginalized cohort. PCPs caring for similar populations should be aware of the potential for both their trust in patients and their interpretation of behaviors to be affected by unconscious racial biases. Our findings add support for the implementation of standardized policies regarding chronic pain management as an alternative to management strategies that rely on PCP discretion. Policies such as urine toxiciology and pain treatment agreements have the potential to standardize care. However, recent evidence suggests that their routine use should be reconsidered because of limited evidence of their effectiveness ${ }^{46}$. As new approaches to chronic pain management are developed, close attention must be paid to the role of providers' unconscious biases, and the potential for racial biases to be translated into disparities in care. Future research on PCPs' trust in patients should target its role as a potential mediator of clinical decision-making, the role of PCP race/ethnicity, as well as whether our findings generalize to other clinical settings and to less marginalized populations.

Funders: Dr. Moskowitz was supported by the Primary Care Research Fellowship at UCSF, funded by HRSA D55HP05165.

This project was supported by NIDA RO1DA022550, NIMH R01MH54907, and NIH/NCRR UCSF-CTSI Grant Number UL1 RRO24131.

\section{Conflicts of Interest: None disclosed.}

Open Access: This article is distributed under the terms of the Creative Commons Attribution Noncommercial License which permits any noncommercial use, distribution, and reproduction in any medium, provided the original author(s) and source are credited.

Corresponding Author: David Moskowitz, MD; Division of General Internal Medicine, University of California San Francisco/San Francisco General Hospital, 3333 California Street, Room 383, 1211, San Francisco, CA 94143 - 1211, USA (e-mail: david. moskowitz@ucsf.edu).

\section{REFERENCES}

1. Thom DH, Campbell B. Patient-physician trust: an exploratory study. J Fam Pract. Feb 1997;44(2):169-76.

2. Grimen H. Power, trust, and risk: some reflections on an absent issue. Med Anthropol Q. Mar 2009;23(1):16-33.

3. Thom DH, Hall MA, Pawlson LG. Measuring patients' trust in physicians when assessing quality of care. Health Aff (Millwood). Jul-Aug 2004;23(4): 124-32.

4. Mechanic D. The functions and limitations of trust in the provision of medical care. J Health Polit Policy Law. Aug 1998;23(4):661-86.

5. Hall MA, Zheng B, Dugan E, et al. Measuring patients' trust in their primary care providers. Med Care Res Rev. Sep 2002;59(3):293-318.

6. Scanlon MN, Chugh U. Exploring physicians' comfort level with opioids for chronic noncancer pain. Pain Res Manag. Winter 2004;9(4):195-201.

7. Merrill JO, Rhodes LA, Deyo RA, Marlatt GA, Bradley KA. Mutual mistrust in the medical care of drug users: the keys to the "narc" cabinet. J Gen Intern Med. May 2002;17(5):327-33.

8. Breitbart W, Kaim M, Rosenfeld B. Clinicians' perceptions of barriers to pain management in AIDS. J Pain Symptom Manage. Sep 1999;18 (3):203-12.

9. Berg KM, Arnsten JH, Sacajiu G, Karasz A. Providers' experiences treating chronic pain among opioid-dependent drug users. J Gen Intern Med. Apr 2009;24(4):482-8.

10. Ives TJ, Chelminski PR, Hammett-Stabler CA, et al. Predictors of opioid misuse in patients with chronic pain: a prospective cohort study. BMC Health Serv Res. 2006;6:46.

11. Edlund MJ, Steffick D, Hudson T, Harris KM, Sullivan M. Risk factors for clinically recognized opioid abuse and dependence among veterans using opioids for chronic non-cancer pain. Pain. Jun 2007;129(3):355-62.

12. Chabal C, Erjavec MK, Jacobson L, Mariano A, Chaney E. Prescription opiate abuse in chronic pain patients: clinical criteria, incidence, and predictors. Clin J Pain. Jun 1997;13(2): 150-5.

13. Green CR, Anderson KO, Baker TA, et al. The unequal burden of pain: confronting racial and ethnic disparities in pain. Pain Med. Sep 2003;4 (3):277-94.

14. Burgess DJ, Crowley-Matoka M, Phelan S, et al. Patient race and physicians' decisions to prescribe opioids for chronic low back pain. Soc Sci Med. Dec 2008;67(11):1852-60.

15. Mills AM, Shofer FS, Boulis AK, Holena DN, Abbuhl SB. Racial disparity in analgesic treatment for ED patients with abdominal or back pain. Am J Emerg Med. Apr 302010. 
16. Green CR, Wheeler JR, Marchant B, LaPorte F, Guerrero E. Analysis of the physician variable in pain management. Pain Med. Dec 2001;2 (4):317-27.

17. Crowley-Matoka M. Political and moral economies of managing pain. American Anthropological Association annual meeting. Washington, DC; 2005.

18. Henderson S, Stacey CL, Dohan D. Social stigma and the dilemmas of providing care to substance users in a safety-net emergency department. J Health Care Poor Underserved. 2008 Nov 2008; 19(4):1336-49.

19. Stepanikova I, Cook, KS, Thom, DH, Kramer, RM, Mollborn, SB. Trust in Managed Care Settings: Physicians' Perspective. In: Karen S. Cook KS LM, Hardin R, ed. Who Can We Trust?: How Groups, Networks, and Institutions Make Trust Possible. Thousand Oaks, CA: Rusell Sage Foundation; 2009

20. van Ryn M, Burke J. The effect of patient race and socio-economic status on physicians' perceptions of patients. Soc Sci Med. Mar 2000;50 (6):813-28.

21. Robertson MJ, Clark RA, Charlebois ED, et al. HIV seroprevalence among homeless and marginally housed adults in San Francisco. Am J Public Health. Jul 2004;94(7):1207-17.

22. Zolopa AR, Hahn JA, Gorter R, et al. HIV and tuberculosis infection in San Francisco's homeless adults. Prevalence and risk factors in a representative sample. Jama. Aug 10 1994;272(6):455-61.

23. Horton J, Compton, W, Cottler, L. Assessing Psychiatric Disorders Among Drug Users: Reliability of The Revised DIS-IV. In: Harris L, ed. NIDA Research Monograph-Problems of Drug Dependence. Washington, D.C: NIH; 1998.

24. Williams ML, Freeman RC, Bowen AM, et al. A comparison of the reliability of self-reported drug use and sexual behaviors using computer-assisted versus face-to-face interviewing. AIDS Educ Prev. Jun 2000;12(3): 199-213.

25. Thom DH WS, Guzman D, Wu A, Penko J, Miaskowski C, Kushel M. Physician Trust in the Patient: Development and Validation of a New Measure. Ann Fam Med. in press.

26. Horton J CW, Cottler L. Assessing Psychiatric Disorders Among Drug Users: Reliability of The Revised DIS-IV. Washington DC: National Institutes of Health; 1998.

27. Nicholson B, Passik SD. Management of chronic noncancer pain in the primary care setting. South Med J. Oct 2007;100(10):1028-36.

28. Zeger SL, Liang KY. Longitudinal data analysis for discrete and continuous outcomes. Biometrics. Mar 1986;42(1):121-30.

29. Liang K-Y, Zeger SL. Longitudinal data analysis using generalized linear models. Biometrika. 1986;73(1):13-22.

30. Green AR, Carney DR, Pallin DJ, et al. Implicit bias among physicians and its prediction of thrombolysis decisions for black and white patients. J Gen Intern Med. Sep 2007;22(9):1231-8.
31. Chen M, Bargh, JA. Nonconscious behavioral confirmation processes: The self-fulfilling consequences of automatic stereotype activation. J Exp Soc Psychol. 1997;35(5):541-60.

32. Devine P. Stereotypes and prejudice: Their automatic and controlled components. J Pers Soc Psychol. 1989;56(1):5-18.

33. Wittenbrink B, Judd, C M, Park, B. Evidence for racial prejudice at the implicit level and its relationship with questionnaire measures. J Pers Soc Psychol 1997;72(2):262-74.

34. van Ryn M. Research on the provider contribution to race/ethnicity disparities in medical care. Med Care. Jan 2002;40(1 Suppl):I140-151.

35. Burgess DJ, van Ryn M, Crowley-Matoka M, Malat J. Understanding the provider contribution to race/ethnicity disparities in pain treatment: insights from dual process models of stereotyping. Pain Med. Mar-Apr 2006;7(2):119-34.

36. Burgess DJ. Are providers more likely to contribute to healthcare disparities under high levels of cognitive load? How features of the healthcare setting may lead to biases in medical decision making. Med Decis Making. Mar-Apr 2010;30(2):246-57.

37. Chen I, Kurz J, Pasanen M, et al. Racial differences in opioid use for chronic nonmalignant pain. J Gen Intern Med. 2005 Jul 2005;20(7):593-8.

38. Dimsdale JE. Stalked by the past: the influence of ethnicity on health. Psychosom Med. Mar-Apr 2000;62(2):161-70.

39. Ng B, Dimsdale JE, Rollnik JD, Shapiro H. The effect of ethnicity on prescriptions for patient-controlled analgesia for post-operative pain. Pain. Jul 1996;66(1):9-12.

40. Godin P. Trust built on shared power. Nurs Stand. Nov 26-Dec 2 2008;23(12):62-3.

41. Thom DH, Ribisl KM, Stewart AL, Luke DA. Further validation and reliability testing of the Trust in Physician Scale. The Stanford Trust Study Physicians. Med Care. May 1999;37(5):510-7.

42. Mead N, Bower P. Patient-centredness: a conceptual framework and review of the empirical literature. Soc Sci Med. Oct 2000;51 (7): $1087-110$.

43. Haas JS, Cook EF, Puopolo AL, Burstin HR, Cleary PD, Brennan TA. Is the professional satisfaction of general internists associated with patient satisfaction? J Gen Intern Med. Feb 2000;15(2):122-8.

44. Sabin J, Nosek BA, Greenwald A, Rivara FP. Physicians' implicit and explicit attitudes about race by MD race, ethnicity, and gender. $\mathrm{J}$ Health Care Poor Underserved. Aug 2009;20(3):896-913.

45. Saha S, Komaromy M, Koepsell TD, Bindman AB. Patient-physician racial concordance and the perceived quality and use of health care. Arch Intern Med. May 10 1999;159(9):997-1004.

46. Starrels JL, Becker WC, Alford DP, Kapoor A, Williams AR, Turner BJ. Systematic review: treatment agreements and urine drug testing to reduce opioid misuse in patients with chronic pain. Ann Intern Med. Jun 1 2010;152(11):712-20. 